Bangladesh J. Sci. Ind. Res. 42(2), 187-194, 2007

\title{
A Mathematical Model for the Benzylation of $p$-Cresol with Benzyl Alcohol
}

\author{
M. Ismail, M. S. Jamal, S. T. A. Islam, M. Z. Alam, M. Ashaduzzaman and M. Saha \\ Department of Applied Chemistry and Chemical Technology, University of Dhaka, \\ Dhaka-1000, Bangladesh
}

\begin{abstract}
The reaction of $p$-cresol with benzyl alcohol in the presence of perchloric acid produces only 2-benzyl-4-methylphenol in high yield. A mathematical model has been developed for the process by Yates pattern experimental design.
\end{abstract}

\section{Introduction}

Benzylated phenols can be used as antioxidants in synthetic rubber, polypropylene, lubricating oil, wax, paper and lard (Filbey et al. 1985; Ravikovich, 1964). Some of the phenol derivatives are strong herbicides, bactericides and insecticides (Melinikov et al. 1954; Nemetkin et al. 1951). Isomeric cresols have been alkylated with different alcohols in the presence of different catalyst by several authors (Abdurasulev et al. 1965; Abdurasulev et al. 1969; Rana et al. 2003; Saha and Roy 1989; Saha and Badruzzaman, 1990; Saha et al. 1996 and Saha et al. 1997). Reports are also available on the benzylation of phenol, cresols, xylenols, chlorophenol and 2,4,6-tribromophenol (Fukumoto et al. 1996; Saha et al. 2001; Saha et al. 2005 and Wang and Ming 1993). But no attempt yet has so far been made to investigate reaction of $p$-cresol with benzyl alcohol in the presence of perchloric acid as a catalyst.
In the present work, the reaction of $p$-cresol with benzyl alcohol in the presence of perchloric acid has been investigated and a mathematical model of the reaction has been developed.

\section{Materials and Methods}

Chemicals used in the present work were of reagent grade. The reactions were carried out in a three necked round bottomed flask fitted with a condenser, a thermometer, a dropping funnel and a magnetic stirrer. $p$-Cresol (30g) and perchloric acid (0.3-1.5g) were charged into the flask and heated to the desired temperature and benzyl alcohol (7.5-10g) was introduced into the mixture gradually for a certain period of time (time of addition) with constant stirring. The reaction mixture was stirred for another period of time (time of stirring) at the same temperature after the complete addition of total amount of benzyl 
alcohol. The reaction mass was then cooled to room temperature, dissolved in petroleum ether, neutralized, washed with distilled water several times and subjected to distillation. Unreacted reactants and solvent were distilled off at atmospheric pressure. The residual product was finally distilled (b.p. $308^{\circ} \mathrm{C}$ ) and the yield (based on benzyl alcohol) was expressed as percentage of theory. Structure of the product was elucidated by spectral means.

\section{Results and Discussion}

p-Cresol with benzyl alcohol in the presence of $60 \%$ perchloric acid (aqueous) as catalyst gave 2-benzyl-4-methylphenol. Three parameters viz. temperature, molar ratio of $p$-cresol to benzylalcohol and amount of perchloric acid were considered in the development of the mathematical model of the reaction of $p$-cresol with benzyl alcohol in the presence of perchloric acid using Yates pattern experimental design (Clausen, 1978).

The experimental ranges of the variables are listed in Table I. The critical response of interest was yield of 2-benzyl-4-methylphenol. Time of addition of benzyl alcohol to cresol-catalyst mixture was $2 \mathrm{~h}$ and time of stirring after the addition of benzyl alcohol was $1 \mathrm{~h}$.

The experimental design used was Yates pattern, 3 factor two level factorial; there were $2^{3}$ i.e. eight trials. Since the basic $2^{3}$ factorial design involves eight trials, each was run in duplicate yielding 16 trials. In order to check the lack of fit due to curvature, additional trial was made at the midpoint level of each factor. The difference between the average centre point value and the overall average of the design points indicated the severity of curvature.

Table II illustrates the two level 3-factor design with the factors in coded form. The experimental runs for trial 1 through 8 were run in duplicate; trial 9, the centre point trial was run four times, interspersed throughout the experimental run.

The results of these experiments are listed in the Table III. The average yield $\bar{Y}$, the range

Table I. Process variables and response

\begin{tabular}{l|c|c|c}
\hline \multicolumn{1}{c|}{ Variable } & \multicolumn{3}{|c}{ Range } \\
\cline { 2 - 4 } & Low (-) & Mid (0) & High (+) \\
\hline $\mathrm{X}_{1}$, Temperature $\left({ }^{\mathrm{O}} \mathrm{C}\right)$ & 70 & 100 & 130 \\
$\mathrm{X}_{2}$, Molar ratio of $p$-cresol to benzyl alcohol & $3: 1$ & $3.5: 1$ & $4: 1$ \\
$\mathrm{X}_{3}$, Amount of catalyst, \% by wt. of $p$-cresol & 1.0 & 3.0 & 5.0 \\
\hline
\end{tabular}

Y, Response : Yield of 2-benzyl-4-methylphenol 
Table II. Experimental design

\begin{tabular}{c|c|c|c|c}
\hline \multirow{2}{*}{ Trial no. } & \multirow{2}{*}{ Replicates } & \multicolumn{3}{|c}{ Design } \\
\cline { 3 - 5 } & & Temperature, $\mathrm{X}_{1}$ & Molar ratio, $\mathrm{X}_{2}$ & Amount of catalyst, $\mathrm{X}_{3}$ \\
\hline 1 & 2 & - & - & - \\
2 & 2 & + & - & - \\
3 & 2 & - & + & - \\
4 & 2 & + & + & - \\
5 & 2 & - & - & + \\
6 & 2 & + & + & + \\
7 & 2 & - & + & + \\
8 & 2 & + & 0 & + \\
9 & 4 & 0 & & 0 \\
\hline
\end{tabular}

Table III. Results of three-factor experiment

\begin{tabular}{c|c|c|c|c|c}
\hline \multirow{2}{*}{ Trial no. } & \multicolumn{5}{|c}{ Results } \\
\cline { 2 - 6 } & \multicolumn{5}{|c}{ Yield, \% } \\
\hline & Y $_{1}$ & Y $_{2}$ & $\bar{Y}$ & Range & Variances \\
\hline 1 & 30.4 & 31.2 & 30.8 & 1 & 0.32 \\
2 & 46.9 & 48.1 & 47.5 & 1 & 0.72 \\
3 & 37.4 & 38.4 & 37.9 & 1 & 0.50 \\
4 & 50.6 & 51.8 & 51.2 & 1 & 0.72 \\
5 & 70.6 & 72.0 & 71.3 & 1 & 0.98 \\
6 & 85.0 & 86.8 & 85.9 & 2 & 1.62 \\
7 & 77.4 & 79.0 & 78.2 & 2 & 1.28 \\
8 & 90.1 & 92.3 & 91.2 & 2 & 2.42 \\
9 & 60.2 & 61.5 & & & \\
& 60.7 & 62.0 & 61.1 & 2 & 0.647 \\
\hline
\end{tabular}

and the variance were calculated for each trial. The variance, which is an estimate of dispersion of data, was calculated by the following formula :

Variance $=\mathrm{S}^{2}=$

$$
\frac{\left(Y_{1}-\bar{Y}\right)^{2}+\left(Y_{2}-\bar{Y}\right)^{2}+\ldots \ldots \ldots+\left(Y_{n}-\bar{Y}\right)^{2}}{n-1}
$$

where $Y=$ response value, $\bar{Y}=$ average or mean of response values, $n=$ number of observations

For example, for trial 1,

$$
\text { Variance } \begin{aligned}
=\mathrm{S}_{1}{ }^{2} & =\frac{(30.4-30.8)^{2}+(31.2-30.8)^{2}}{2-1} \\
& =0.16+0.16=0.32
\end{aligned}
$$

and for trial 9, 
Variance $=\mathrm{S}_{9}{ }^{2}=$

$\frac{(60.2-61.1)^{2}+(60.7-61.1)^{2}+(61.5-61.1)^{2}+(62.0-61.1)^{2}}{4-1}$

$=0.647$

The variances calculated for each trial were then used in the calculation of a weighted average of the individual variances for each trial.

Pooled variance $=\mathrm{S}_{\text {pooled }}^{2}=$

$\frac{\left(n_{1}-1\right)\left(S_{1}{ }^{2}\right)+\left(n_{2}-1\right)\left(S_{2}{ }^{2}\right)+\ldots \ldots .+\left(n_{K}-1\right)\left(S_{K}{ }^{2}\right)}{\left(n_{1}-1\right)+\left(n_{2}-1\right)+\ldots \ldots \ldots \ldots \ldots+\left(n_{K}-1\right)}$

$=\frac{0.32+0.72+0.50+0.72+0.98+1.62+1.28}{1+1+1+1+1+1+1+1+3}$

$$
\underline{+2.42+3 \times 0.647}=0.955
$$

The pooled standard deviation is the square root of the pooled variance :

$$
\begin{aligned}
\text { Standard deviation }_{\text {pooled }} & =\sqrt{S^{2}{ }_{\text {pooled }}} \\
& =\sqrt{0.955}=0.977
\end{aligned}
$$

The pooled standard deviation used to calculate the minimum observed effect that was statistically significant.

The computation analysis for this experiment is shown in the Table IV. The design matrix was supplemented with a computation matrix, which was used to detect any interaction effect. This computation matrix was generated by simple algebraic multiplication of the coded factor levels. In trial $1, \mathrm{X}_{1}$ was minus, $X_{2}$ was minus, therefore, $X_{1} X_{2}$ was plus; in trial 2, $X_{1}$ was plus, $X_{2}$ was minus, therefore $\mathrm{X}_{1} \mathrm{X}_{2}$ was minus. The column at the far right of the table is the average yield for each trial. The sum +'s row was generated by totaling the response values on each row with a plus for each column. For $\mathrm{X}_{1}$ factor, $47.5+$ $51.2+85.9+91.2=275.8$. In the similar manner the sum -'s row was generated. The sum of these two rows should equal the sum of all the average responses and was included as a check on the calculations. The difference row represented the difference between the responses in the four trials when the factor was at a high level and the responses in the four trials when the factor was at a low level. The effect was then calculated by dividing the difference by the number of plus signs in the column.

In the first column, labeled mean, the effect row value was the mean or average of all data points. The average of the centre point runs, Trial 9, was then subtracted from the mean effect to give a measure of curvature.

The minimum significant factor effect [MIN] and the minimum significant curvature effect [MINC] were again derived from t-test significance criteria. The relationships are:

$$
\begin{aligned}
& {[\mathrm{MIN}]=\mathrm{t} . \mathrm{s} \sqrt{\frac{2}{m \cdot k}}} \\
& {[\mathrm{MINC}]=\mathrm{t} . \mathrm{s} \sqrt{\frac{1}{m \cdot k}+\frac{1}{c}}}
\end{aligned}
$$

where $\mathrm{t}$ = appropriate value from " $\mathrm{t}$ - table", $\mathrm{s}=$ pooled standard deviation, $\mathrm{m}=$ number of 
plus signs in column, $\mathrm{k}=$ number of replicates in each trial, $\mathrm{c}=$ number of centre points. The $t$ value of 2.20 is from the student's "t" table for the $95 \%$ confidence level and 11 degrees of freedom (Davies, 1979). The degrees of freedom result from eight trials with two replicates and one trial with four replicates.

Degrees of freedom $=8(2-1)+1(4-1)=11$

The calculations for the minimum significant effects are as follows:

$[\mathrm{MIN}]=2.20 \times 0.977 \times \sqrt{\frac{2}{4 \times 2}}=1.075$

$[\mathrm{MINC}]=2.20 \times 0.977 \times \sqrt{\frac{2}{8 \times 2}+\frac{1}{4}}=1.202$
Applying these criteria to the calculated effects, it was seen that the effects of temperature $\left(\mathrm{X}_{1}\right)$, molar ratio of $p$-cresol to benzyl alcohol $\left(\mathrm{X}_{2}\right)$, amount of perchloric acid $\left(\mathrm{X}_{3}\right)$ and interaction between temperature and molar ratio of $p$-cresol to benzyl alcohol $\left(\mathrm{X}_{1} \mathrm{X}_{2}\right)$ were significant. There was no significant curvature effect. These results were expressed as a mathematical model using a first order polynomial. The values for the co-efficient were one half the factor effects listed in the Table IV. Since these were based upon coded levels +1 and -1 that differed by two units.

$Y=61.75+7.2 X_{1}+2.875 X_{2}+19.9 X_{3}-0.625 X_{1} X_{2}$

Table IV. Computation matrix for three factor experiment

\begin{tabular}{|c|c|c|c|c|c|c|c|c|c|}
\hline \multirow[t]{2}{*}{ Trial } & \multirow[t]{2}{*}{ Mean } & \multicolumn{3}{|c|}{ Design } & \multicolumn{4}{|c|}{ Computation } & \multirow{2}{*}{ Response } \\
\hline & & $\mathrm{X}_{1}$ & $\mathrm{X}_{2}$ & $\mathrm{X}_{3}$ & $\mathrm{X}_{1} \mathrm{X}_{2}$ & $\mathrm{X}_{1} \mathrm{X}_{3}$ & $\mathrm{X}_{2} \mathrm{X}_{3}$ & $\mathrm{X}_{1} \mathrm{X}_{2} \mathrm{X}_{3}$ & \\
\hline 1 & + & - & - & - & + & + & + & - & 30.8 \\
\hline 2 & + & + & - & - & - & - & + & + & 47.5 \\
\hline 3 & + & - & + & - & - & + & - & + & 37.9 \\
\hline 4 & + & + & + & - & + & - & - & - & 51.2 \\
\hline 5 & + & - & - & + & + & - & - & + & 71.3 \\
\hline 6 & + & + & - & + & - & + & - & - & 85.9 \\
\hline 7 & + & - & + & + & - & - & + & - & 78.2 \\
\hline 8 & + & + & + & + & + & + & + & + & 91.2 \\
\hline Sum +'s & 494.0 & 275.8 & 258.5 & 326.6 & 244.5 & 245.8 & 247.7 & 247.9 & \\
\hline Sum -'s & 0.0 & 218.2 & 235.5 & 167.4 & 249.5 & 248.2 & 246.3 & 246.1 & \\
\hline Sum & 494.0 & 494.0 & 494.0 & 494.0 & 494.0 & 494.0 & 494.0 & 494.0 & \\
\hline Diff. & 494.0 & 57.6 & 23.0 & 159.2 & -5.0 & -2.40 & 1.40 & 1.80 & \\
\hline Effect & 61.75 & $14.40^{*}$ & $5.75^{*}$ & $39.8^{*}$ & $-1.25^{*}$ & -0.60 & 0.35 & 0.45 & \\
\hline
\end{tabular}

Curvature $=61.75-61.10=0.65$

[Curvature $=$ Mean effect-Average of central point runs $\bar{Y}$ ] 
In this equation, the factors were expressed in coded units. These were converted into real units by substituting:

for temperature $\mathrm{T}\left({ }^{\mathrm{O}} \mathrm{C}\right), \mathrm{X}_{1}=\frac{T-\frac{130+70}{2}}{\frac{130-70}{2}}$

$$
=\frac{T-100}{30}
$$

for molar ratio (m:1), $\mathrm{X}_{2}=\frac{m-\frac{4+3}{2}}{\frac{4-3}{2}}=\frac{m-3.5}{0.5}$ for the amount of catalyst (y), $X_{3}=\frac{y-\frac{5+1}{2}}{\frac{5-1}{2}}$

$$
=\frac{y-3}{2}
$$

These substitutions yielded the following final expression :

$\mathrm{Y}=61.75+7.2 \times\left(\frac{T-100}{30}\right)+2.875 \times\left(\frac{m-3.5}{0.5}\right)$

$+19.9 \times\left(\frac{y-3}{2}\right)-0.625 \times\left(\frac{T-100}{30}\right)\left(\frac{m-3.5}{0.5}\right)$

$=-26.925+0.387+9.95 \mathrm{~m}+9.95 \mathrm{y}-0.042 \mathrm{Tm}$

For trial 1 , temperature $(\mathrm{T})=70^{\mathrm{O}} \mathrm{C}$, molar ratio of $p$-cresol to benzyl alcohol (m:1) $=3: 1$ and the amount of catalyst $(\mathrm{y})=1 \%$ by wt. of $p$-cresol. Therefore, yield calculated from the derived model,

$$
\begin{array}{r}
Y_{\text {(cal.) }}=-26.925+0.38770+9.953+9.95 \\
1-0.042703=31.1
\end{array}
$$

Experimental average yield of the trial 1, $Y_{(\text {exp.) }}=30.8$
Hence, deviation $=0.3$ and percentage deviation $=0.97$

All the values of the experimental average yield and the calculated yield from the derived equation are shown in the Table V.

Table V. Experimental average yield and calculated yield

\begin{tabular}{c|c|c|c|c}
\hline Trial & $\begin{array}{c}\text { Y } \\
\text { (exp.) }\end{array}$ & $\begin{array}{c}\text { Y } \\
\text { (cal.) }\end{array}$ & Deviation & $\begin{array}{c}\text { Percentage } \\
\text { deviation }\end{array}$ \\
\hline 1 & 30.8 & 31.1 & 0.3 & 0.97 \\
2 & 47.5 & 46.8 & 0.7 & 1.47 \\
3 & 37.9 & 38.2 & 0.3 & 0.79 \\
4 & 51.2 & 51.3 & 0.1 & 0.20 \\
5 & 71.3 & 70.9 & 0.4 & 0.56 \\
6 & 85.9 & 86.6 & 0.7 & 0.81 \\
7 & 78.2 & 78.0 & 0.2 & 0.25 \\
8 & 91.2 & 91.1 & 0.1 & 0.11 \\
\hline
\end{tabular}

The discrepancies between the experimental and calculated values did not exceed $1.47 \%$.

Formation of 2-benzyl- 4-methylphenol can be shown by the following mechanism :

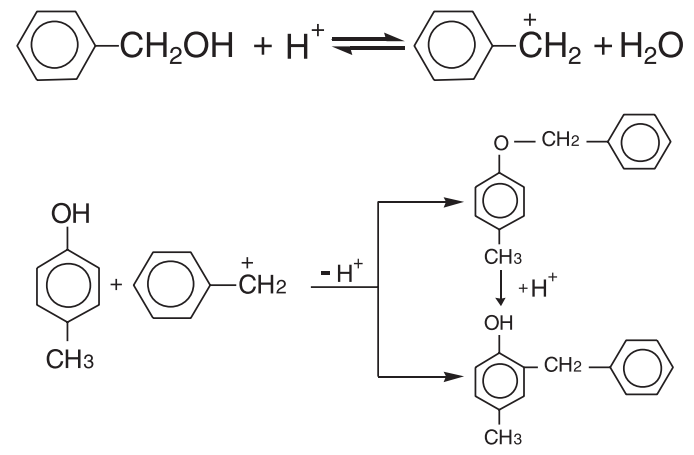

The product showed strong absorption at $\lambda_{\max }$ $=291.0 \mathrm{~nm}$ in $0.01 \mathrm{M}$ methanol solution in the UV- spectrum. 
The IR spectrum of the product showed absorption bands at $810 \mathrm{~cm}^{-1}$ and $880 \mathrm{~cm}^{-1}$ for the 1, 2, 4- trisubstituted benzene ring. Absorption bands at $3510 \mathrm{~cm}^{-1}, 3020 \mathrm{~cm}^{-1}$, $2900 \mathrm{~cm}^{-1}$ and $1595 \mathrm{~cm}^{-1}$ indicated the presence of $-\mathrm{OH}$ group, aromatic $=\mathrm{C}-\mathrm{H}$, saturated $\mathrm{C}-\mathrm{H}$ and benzene ring $\mathrm{C} \stackrel{\mathrm{C}}{\mathrm{C}}$ stretch, respectively.

The ${ }^{1} \mathrm{H}$ NMR spectrum of 2-benzyl-4-methyl phenol showed in the Table VI.

Table VI The ${ }^{1} \mathrm{H}$ NMR spectrum of 2-benzyl- 4-methyl phenol

\begin{tabular}{c|c}
\hline Observed signals of the protons & $\begin{array}{c}\text { Chemical } \\
\text { shift in } \delta \mathrm{ppm}\end{array}$ \\
\hline $\begin{array}{c}\text { Three }-\mathrm{CH}_{3} \text { group protons } \\
\text { Two protons of }-\mathrm{CH}_{2} \text { - on } \\
\text { benzyl group }\end{array}$ & 2.00 \\
$\begin{array}{c}\text { One proton on the -OH group } \\
\text { Eight protons on the two } \\
\text { aromatic rings }\end{array}$ & $5.60-3.90$ \\
\hline
\end{tabular}

\section{References}

Abdurasulev, A.R. Aliev, N.K. Kakharov, A.T. and Yotdashev, Y. (1965) Alkylation of cresols with cyclohexanol and cyclopcntanol. Zh. Obsh. Khim. 1(3) : 517-521.

Abdurasulev, A.R. Ismailov, N. and Yotdashev, Y. (1969) Alkylation of cresols by cyclohexanol in the presence of KU-2 cation exchanger. Zh. Obsh. Khim. 13(5) : 50-52.

Clausen, C.A. and Metson, G. (1978) Principle of Industrial Chemistry. (Willy Interscience Publication, New York), pp 412.
Davies O.L, (1979) Design and Analysis of Industrial Experiments. 2nd Ed. (Longman, London) pp 636.

Filbey, A.H. Braxton, H.G. and Meltsner. R. B. (1985) Benzylation of phenols with benzyl alcohol. U.S 4514577 (Cl. 588-744; C07C 391/14). Chem. Abstr. 103 : 37198s.

Fukumoto, S. Fukushi, S. Terao, S. and Shiraishi, M. (1996) Direct and enantiospecific orthobenzylation of phenols by the Mitsunobu reaction. J. Chem. Soc., Perkin Trans.10 : 1021-1026.

Melinikov, N.N. Baskakov, Y.A. and Bokrev, K.S. (1954) Chemistry of Herbicides and Plants Growth Regulators. Gkhi. Moskow. 38.

Nemetkin, S.S. Baskahov, Y.A. and Melnikov, N.N. (1951) Synthesis of some alkyl and arylkyl phenoxyacetic acid. Zh. Obsh. Khim. 12 : 2146-2150.

Rana, A. A. Kamruzzaman, M. Sarker, M. A. B. Alam, A. and Saha, M. (2003) Benzylation of cresols with benzyl alcohol in the presence of sulphuric acid. Dhaka Univ. J. Sci. 51(2) : 169-178.

Ravikovich, A. M. (1964) Antioxidants for minerals and synthetic oils. Chemistry and Technology for Fuels and Oils, 11, 64-71.

Saha, M. and Roy, R.K. (1989) Study of alkylation of $p$-cresol with n-hexanol. Bangladesh J. Sci. Ind. Res. 24(1-4) : 33-40. 
Saha, M. and Badruzzaman, M. (1990) Comparative studies on the reaction of cresols with alcohols in the presence of benzenesulphonic acid. Bangladesh J. Sci. Res. 8(2) : 213-215.

Saha, M. Mosihuzzaman, M. and Saha, S. (1996) Alkylation of $p$-cresol with cyclohexene in the presence of benzenesulphonic acid. Indian J. Chem. Technol. 3 : 292 - 294.

Saha, M. Jolly, Y. N. Saha, D. and Sarker, M.A.B. (1997) Alkylation of $p$-cresol with n-alcohols. Bangladesh J. Sci. Ind. Res. 32 (1): 67- 69 .
Saha, M. Alam, A. Kamruzzaman, M. and Hasan, M.M. (2001) Benzylation of cresols with benzyl alcohol in the presence of benzene sulphonic acid. Bangladesh J. Sci.Ind. Res. 36(1-4) : 106-108.

Saha, M. Alam, A. Asaduzzaman, M. and Saha, S. K. (2005) Benzylation of xylenols with benzyl alcohol, Bangladesh J. Sci. Ind. Res. 40 (1-2) : 153-156.

Wang, M. L. and Ming, H.Y. (1993) Dynamics of the reaction of 2,4,6-tribromophenol and benzyl bromide by phase transfer catalysis. J. Chem. Eng. Jpn. 26(4) : 374-381.

Received : November 05, 2006;

Accepted : June 10, 2007; 
Adeyeye, Arogundade, Asaolu and Olaofe 
Adeyeye, Arogundade, Asaolu and Olaofe 
Adeyeye, Arogundade, Asaolu and Olaofe 
